\title{
Mathematical analysis and comparison of growth fluctua- tions of the aerial system of young Terminalia superba Englers et Diels (Combretaceae)
}

\author{
P. Maillard ${ }^{1}$, M. Jacques ${ }^{1}$, E. Miginiac ${ }^{1}$ and B. Millet ${ }^{2}$ \\ 1 Institut de Physiologie Végétale (Phytotron), CNRS, Gif-sur-Yvette, 91190, and \\ 2 Laboratoire de Botanique, Institut des Sciences Naturelles, pl. Leclerc, Besançon, 25030, France
}

\section{Introduction}

Under natural conditions, Terminalia superba is a tropical forest tree which shows fluctuations in growth rate and in flushing behavior (Groulez and Wood, 1984). This behavior and particularly the periodic growth cessations were concomitant with the dry season. This rhythmical growth pattern ends in a monopodial main axis and a particular stratified branch system as described by Halle and Oldeman (1970) in Aubreville's model.

In climate chambers at Phytotron, Gifsur-Yvette, we determined the best growth conditions for young $T$. superba (Maillard et al., 1987). Under these conditions $\left(27^{\circ} \mathrm{C}, 16 \mathrm{~h}\right)$, we noted fluctuations in the aerial growth. Thereafter, the purpose of our work was the detailed study of the early developmental stages of this tree. Growth fluctuations were analyzed on young $T$. superba using the Fourier method and rhythmical components of growth were evaluated. The growth relationships between shoot and branches and their effects on tree architecture have been investigated.

\section{Materials and Methods}

\section{Materials}

T. superba seeds originating from Sibiti (Congo), obtained from the Centre Technique Forestier Tropical, Nogent-sur-Marne (ref. C.T.F.T., $82 / 3808 \mathrm{~N}$ ), were used for the experiment. Measurements were made over $1 \mathrm{yr}$, on 3 mo old seedlings in a controlled and conditioned glasshouse $\left(27^{\circ} \mathrm{C}, 16 \mathrm{~h}\right.$ photoperiod and $70 \%$ humidity) at Phytotron, Gif-sur-Yvette.

\section{The Fourier method}

We used the method of Assaad (1985). The fluctuations of individual growth curves obtained from weekly data were studied: the polynomial regression curve, which represents the fitted growth curve, was calculated by the least squares method. The signal without trend was obtained and a subtraction point by point between this polynomial curve and the data curve revealed the growth oscillations. Then, the signal without trend and the estimation of the rhythmical parameters (amplitude, period) were analyzed using the Fourier analysis itself. 


\section{Results}

\section{General observations}

At the end of the experiment, the main stems of the plants were vertical with great variations in the length of constitutive internodes. Generally, in short internode regions, single or groups of 2 or 3 lateral branches arose from the axil of adjacent leaves. These branches were composed of a series of sympodial units that appeared more often in pairs. The

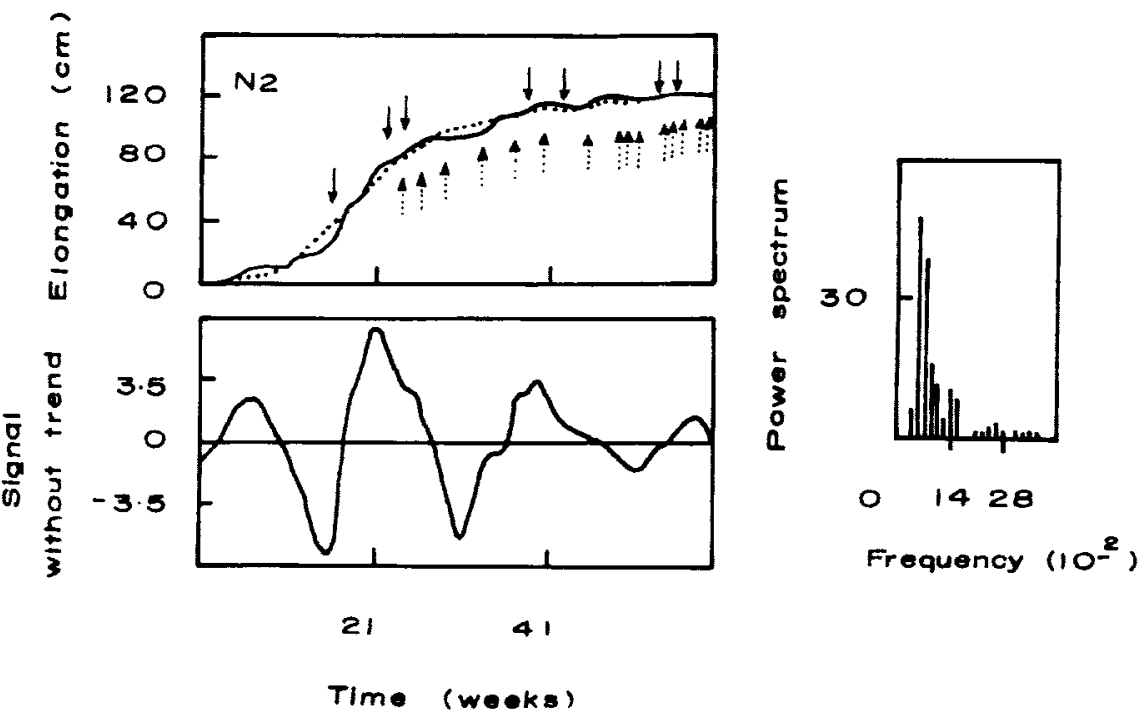

Fig. 1. Estimation by Fourier analysis of hythmical growth variations of the main axis of a young $T$. superba plant during 61 wk. Polynomial curve $(\cdots) ;(\downarrow)$ branch initiation; $(\hat{i})$ appearance of new plagiotropic units.
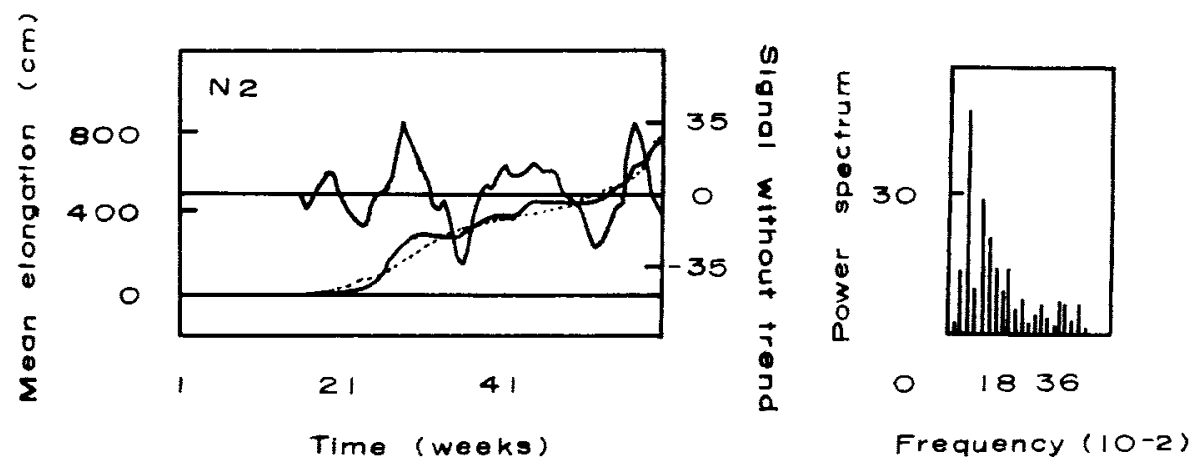

Fig. 2. Estimation by Fourier analysis of hythmical growth variations of axillary branches of a young $T$. superba plant during 61 wk. Polynomial curve $(\cdots)$. 
Table I. Estimation by Fourier analysis of parameters of growth rhythms of the main axis and axillary branches of young $T$. superba, in a controlled greenhouse at $27^{\circ} \mathrm{C}$ and $16 \mathrm{~h}$ photoperiod.

\begin{tabular}{|c|c|c|c|c|c|}
\hline & \multicolumn{5}{|l|}{ Plant } \\
\hline & 1 & 2 & 3 & 4 & 5 \\
\hline \multicolumn{6}{|l|}{ Main axis } \\
\hline period (wk) & 14.3 & 19.7 & 19.3 & 12.2 & 12.2 \\
\hline amplitude $(\mathrm{cm})$ & 2.2 & 3.7 & 1.6 & 1.6 & 2.4 \\
\hline \multicolumn{6}{|l|}{ Lateral branches } \\
\hline period (wk) & 14.7 & 14.7 & 15.0 & 10.5 & 14.7 \\
\hline amplitude $(\mathrm{cm})$ & 7.0 & 15.2 & 4.7 & 16.5 & 18.6 \\
\hline
\end{tabular}

first unit arose alone directly from an axillary bud on the principal axis.

Individual patterns of plant main axis elongation showed a time-lag during the first 11 wk (Fig. 1). Then, growth occurred in the following 21 wk with successive flushes. During the last weeks of the experiment, the elongation of the main axis slowed and entered a low growth phase with many rest intervals. The number of these intervals varied with plants but was usually 3 or 4 .

The development of the first axillary branches occurred from the 11th to the 16th wh after the start of the study (Fig. 1). These branches appeared from the axil of leaves in an area between the 30th and the 55th leaf. The dates of branch initiation on the principal axis showed clearly that axillary buds were able to develop only when the principal axis entered low growth phases or during rest periods (Fig. 1). The subsequent development of initiated branches was made by apposition of new sympodial units that appeared at quite regular intervals, regardless of the periodic elongation of the main shoot (Fig. 1). For each plant, weekly measurements of the extension of all axillary branches were used to establish a cumulative elongation curve (Fig. 2). These curves showed numerous and pronounced variations over the 61 wk of the study. These variations corresponded to the appearance and the growth of new plagiotropic units or the general growth stoppage of the whole branches.

\section{Mathematical analysis}

The nature of fluctuations observed from the aerial growth has been examined by Fourier analysis. Results shown in Table I revealed a wide range in the period of the growth rhythm presented by the main axis. The values of the period varied from 12 to $20 \mathrm{wk}$ and implied that an $8 \mathrm{wk}$ time-lag exists between rest periods and the resumption of the activity of the main axis. This wide range was also seen in the amplitude of the growth rhythm. Consequently, the characteristics of this rhythmical phenomenon were derived from the individual behavior and properties of plants.

The growth of all plagiotropic branches also appeared to be rhythmic and underwent periods of flushes and stoppages. The estimated period remained generally about 15 wk (Table I). The amplitude of the cumulative growth rhythm showed variations for each plant.

For the 61 wk of the experiment, comparison of signals without trend of the principal axis and those of axillary branches revealed a gap between the two rhythms whose period was not always very dif- 
ferent. Consequently, these organs did not reach their maximal growth rate at the same time.

\section{Conclusion}

Our results on the 1st year of the development present the young $T$. superba as a monopodial axis with plagiotropic branches, both undergoing successive flushes. These results supported the preliminary description of adult Terminaliaplants established by Halle and Oldeman (1970). This discontinuous development occurred under non-seasonal conditions and its underlying mechanism could be due to the tree itself. The Fourier analysis used made the rhythmical characteristics of the aerial growth prominent and allowed the estimation of rhythmical parameters under the environmental conditions used. A second type of analysis (for example, the modern spectral analysis employed by Assaad (1985)) could be necessary to compare and to confirm the reliability of the estimated values of rhythms. Our observations indicate that the rhythmical branching growth was directly related to the main axis flushes. In fact, the young branches were initiated as often as the growth of the main stem began to decrease. Such a behavior was also noted in Terminalia by Tomlinson (1976) and probably indicated correlative influences notably exerted between axillary and terminal buds. Finally, the stratified branch system borne on a single trunk of young $T$. superba with these sub-verticills of lateral branches was partly explained by this discontinuous growth pattern.

\section{Acknowledgments}

The C.T.F.T., the forestry department of the C.I.R.A.D. (France), is duly acknowledged for its financial participation.

\section{References}

Assaad C. (1985) Organisation temporelle de la tomate (Lycopersicon esculentum Mill. cv. Ace) au cours de sa croissance et de son développement. Ph.D. Thesis, Université Franche Comté, France

Groulez J. \& Wood P.J. (1984) In: Monographie du Terminalia superba. C.T.F.T., C.F.I., Ed. Française, pp. 85

Halle F. \& Oldeman R.A.A. (1970) Essai sur l'architecture et la dynamique de croissance des arbres tropicaux. Monogr. Bot. Biol. Vég. Masson, Paris, pp. 178

Maillard P., Jacques M. \& Miginiac E. (1987) Croissance de jeunes Terminalia superba en conditions contrôlées. Ann. Sci. For. 44, 67-84

Tomlinson P.B. (1976) Branching and axis differentiation in tropical trees. In: Tropical Trees as Living Systems. (Tomlinson P.B. \& Zimmerman M.H., eds.), Cambridge Univ. Press, Cambridge, pp. 187-207 